\title{
Suppression and recovery of a one-trial avoidance response after a single ECS
}

\author{
R. M. Cooper, ALBERT EINSTEIN COLLEGE OF MEDICINE \\ R. J. Koppenaal, NEW YORK UNIVERSITY
}

\begin{abstract}
Abstraet
Groups of rats were subjected to either a single ECS or no ECS within a few sec. after receiving 1 or 2 punishing shocks in a box in which they had been trained to drink from a water spout. ECS groups drank more (avoided less) than no ECS controls at both 1 and $24 \mathrm{hr}$. after the punishing shocks. Two shock ECS groups tested at $24 \mathrm{hr}$., however, drank less than 2 shock ECS groups tested at $1 \mathrm{hr}$. These results were considered in terms of the notion of memory consolidation.
\end{abstract}

\section{Introduction}

There is evidence that when memory-disturbing events are interpolated between learning and a retention test, the degree of disturbance varies with the length of the retention interval. Thus, it is well established that in the retention of two consecutively learned competing verbal habits the recency effect favoring retention of the second habit dissipates over time (e. g., Underwood, 1948; Koppenaal, 1963). Similarly, Brady and his collaborators (Brady, 1951; Hunt, Jernberg \& Brady, 1952) found a conditioned fear response to be vestigial four days after the last of a series of ECSs but clearly present at 30 days.

The possibility that habit-loss is also somewhat temporary when a single ECS is administered immediately after a learning trial has important implications for the notion of memory consolidation. This notion implies that ECS brings about a permanent impairment in retention.

In the present study an avoidance response established in a single trial, and followed by one ECS, was examined at different intervals after the convulsive treatment. Subjects

Seventy-four female, black-hooded, 200-gm rats, purchased from the Canadian Research Animal Farms, were used. The $30 \mathrm{Ss}$ used in Experiment 1 had prior experience with food deprivation and footshock. The Ss used in Experiment 2 were experimentally naive. Apparatus

A $12 \times 12 \times 10$-in unpainted waxed pine box was fitted with a grid floor and a $1 \times 1 / 2$-in pedal. The pedal was located beneath a water spout on one wall. Slight pressure on the pedal closed a circuit initiating a recording device. The pedal had no control over water delivery but was so situated that when drinking from the spout $\mathrm{S}$ would almost always press it down. On test days E monitored the drinking response via a mirror suspended above the box. By manipulating a switch E delivered a 0.5-sec. punishing shock of 5 to 8 ma. to $S$ on the grid or when $S$ was in contact v.ith the water spout or pedal ( $500 \mathrm{v}, 40 \mathrm{~K}$ resistance, delivered to the grid, spout and pedal). This punishing shock was sufficient to make the Ss attempt to jump out of the box when the lucite top was opened and bite E's gloved hand when picked up. ECS was induced by administering a current of $50 \mathrm{ma}$. for $0.2 \mathrm{sec}$, via saline-soaked, gauze-covered, alligator clips attached to S's ears ( $500 \mathrm{v}, 0$ resistance, delivered to the clips). Procedure

The Ss were placed on a $231 / 2-\mathrm{hr}$. water deprivation schedule for three days prior to daily $10-\mathrm{min}$. adaptation-drinking sessions in boxes similar to the one described above. Four or five days later the Ss were placed in the test box and drinking time was recorded for $3 \mathrm{~min}$. on each of three successive days. By this time most Ss showed a stabilized drinking response. Experimental treatments were administered on the following day.

Throughout the experiment Ss were introduced into the box against the wall opposite that containing the pedal and water spout. On the final three days of pretraining and on the treatment day, a vertical lucite partition was lowered half-way between the above walls after $\mathrm{S}$ had approached the water spout. This prevented return to the starting point and localized all punishing shocks in the half of the box nearest the water spout and pedal.

One min. after $\mathrm{S}$ was placed in the box on the treatment day $\mathrm{E}$ closed the punishing shock switch if $\mathrm{S}$ was drinking or as soon as $\mathrm{S}$ did drink. Some Ss received a second punishing shock 5 sec. after the first. Immediately after the punishing shock, $\mathrm{S}$ was removed from the box and ECS or control procedures were carried out within $30 \mathrm{sec}$.

Experiment 1 consisted of seven groups, chosen in a semirandomized fashion to ensure that no group was weighted with Ss that drank relatively infrequently. These groups were subjected to the various treatments indicated in Fig. 1. In Experiment 2, similar to the first, three groups were added making a total of 10 . Figure 2 indicates the various treatments they received.

Ss that underwent $24-\mathrm{hr}$. retention tests were given access to water 1 to $2 \mathrm{hr}$. after ECS on a stand that was used during training. One-hr. retention groups did not receive water during the interval. The same number of hours of water deprivation preceded the 1-hr. and $24-\mathrm{hr}$. retention tests.

\section{Kesults}

Figure 1, depicting the results of Experiment 1, shows that ECS Ss drank more than no-ECS Ss. It also indicates that 2-shock ECS Ss tested at $24 \mathrm{hr}$. drank less than 2 -shock ECS Ss tested at $1 \mathrm{hr} .(U=1 ; p<.006)$. The difference between the 1-shock ECS groups tested at 1 and $24 \mathrm{hr}$. is not significant $(U=7 ; p=.7)$.

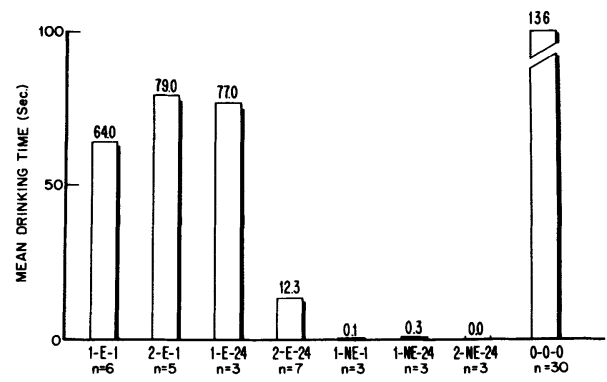

Fig. 1. Mean drinking times during 180-sec. period for groups: $1-\mathrm{E}-1$ ( 1 shock, ECS, retention test at $1 \mathrm{hr}$.), 2-E-1 ( 2 shocks, ECS, retention test at $1 \mathrm{hr}$.), 1-E-24 (1 shock, ECS, retention test at $24 \mathrm{hr}.), 2-\mathrm{E}-24$ (2 shocks, ECS, retention test at $24 \mathrm{hr}.), 1-\mathrm{NE}-1$ (1 shock, no ECS, retention test at $1 \mathrm{hr}.), 1-\mathrm{NE}-24$ (1 shock, no ECS, retention test at $24 \mathrm{hr}$.), 2-NE-24 (2 shocks, no ECS, retention test at $24 \mathrm{hr}$.) and 0-0-0 (the mean drinking time of Ss on the last day of preliminary training). 


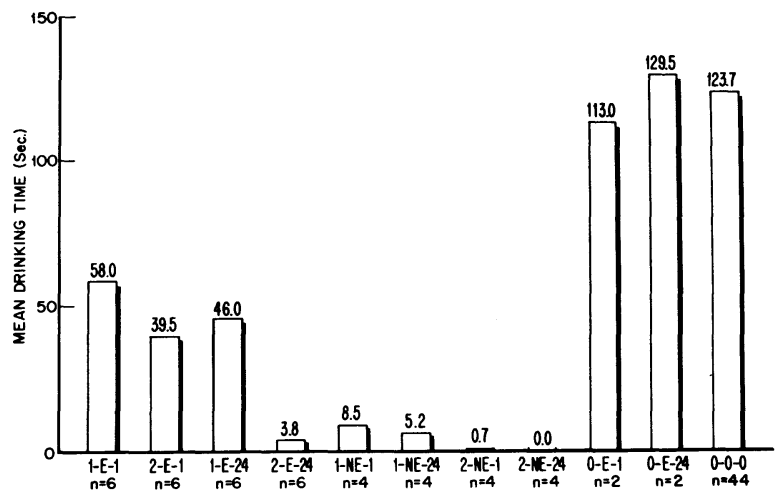

Fig. 2. See legend under Fig. 1. The last 2 groups (0-E-1 and $0-E-24)$ shown on the right side of the figure designate Ss receiving ECS-only and subsequent drinking tests at 1 and $24 \mathrm{hr}$. respectively.

The results of Experiment 2, shown in Fig. 2, are similar to the first: ECS groups drank more than no-ECS groups; the 2-shock ECS Ss tested at $1 \mathrm{hr}$. drank more than 2-shock ECS Ss tested at $24 \mathrm{hr} .(\mathrm{U}=6.5 ; \mathrm{p}<.05$, one-tail); and there was no significant difference between the 1-shock 1- and 24-hr. ECS groups $(U=16.5$; $\mathrm{p}=.82$ ). Figure 2 also indicates that ECS by itself does not seem to disrupt subsequent drinking at 1 and $24 \mathrm{hr}$.

While half of the no-ECS Ss had clips applied to their ears and half did not, these subgroups were combined in the figures since there were no indications of differences.

\section{Diseussion}

The increase in avoidance behavior from 1 to $24 \mathrm{hr}$. by 2-shock, ECS animals may indicate that ECS does not impair the formation of a memory trace, but somehow interferes with its expression in behavior. That this suppression effect is not simply attributable to a temporary, postictal, general confusional state is indicated by several observations: loss of retention was signified by an active drinking response; there was no difference between 1-shock ECS 1-hr. and 24-hr. retention groups; and ECS-only Ss drank normally at $1 \mathrm{hr}$. The lack of recovery of the avoidance response in the 1-shock, ECS 24-hr. retention groups is not clearly contradictory since it is possible that a weaker habit would be suppressed by ECS for a longer duration. Unfortunately we could not establish an avoidance response in one trial that showed stability over longer periods of time.

While there is significant similarity between the results of the present work and those of Brady (1951) and Hunt et al. (1952), they seem to differ in one respect. Their studies showed that paralleling the return of the fear response in the ECS rats there was a similar though lesser gain in no-ECS animals. Possibly the slight but insignificant tendency for all four 24-hr. shocked groups to show greater avoidance than respective 1-hr. groups in Experiment 2 reflects a similar effect. If a fear "incubation" process (Kamin, 1957, 1963) was occurring in our animals, then it is possible that the one $24 \mathrm{hr}$. difference reflects a growth in strength of the avoidance habit in addition to recovery from ECS suppression.

The best evidence for the consolidation interpretation of ECS effects is the general finding that the longer the interval between habit acquisition and ECS, the less the effect of the convulsions on memory (Glickman, 1961; Heriot \& Coleman, 1962). It is difficult to reconcile the consolidation interpretation, however, with the fact that Brady (1952) found the same effect over intervals (60-90 days) which seem outside the bounds of a neural perseveration process. If fear incubation is a general phenomenon, these findings may be compatible with a suppression interpretation. With longer intervals between acquisition and ECS an incubated fear response, with greater habit strength, would be less subject to suppression by the convulsions.

Whether the foregoing speculations prove useful or not the present study, as well as those of Hunt et al., do not support two current interpretations of the effects of ECS on retention. The competition of response hypotheses of Coons \& Miller (1960) and Lewis \& Adams (1963) are not supported because loss of retention was demonstrated by an active approach response. Since the consolidation hypothesis (Glickman, 1961) implies permanent impairment of the trace the demonstration that ECS may only temporarily suppress retention is conflicting evidence for that interpretation.

\section{References}

BRADY, J. V. The effect of electro-convulsive shock on a conditioned emotional response: The permanence of the effect.J.comp. physiol. Psychol., 1951, 44, 507-511.

BRADY, J. V. The effect of electro-convulsive shock on a conditioned emotional response: The significance of the interval between the emotional conditioning and the electro-convulsive shock. J.comp. physiol. Psychol., 1952, 45, 9-13.

COONS, E. E., \& MILLER, N. E. Conflict versus consolidation of memory traces to explain "retrograde amnesia" produced by ECS. J. comp. physiol. Psychol., 1960, 53, 524-531.

GLICKMAN, S. E. Perseverative neural processes and consolidation of the memory trace. Psychol. Bull., 1961, 58, 218-233.

HERIOT, J. T., \& COLEMAN, P. D. The effect of electroconvulsive shock on retention of a modified "one-trial" conditioned avoidance. J. comp. physiol. Psychol., 1962, 55, 1082-1084.

HUNT, H. F., JERNBERG, P., \& BRADY, J. V. The effect of electroconvulsive shock (ECS) on a conditioned emotional response: The effect of post-ECS extinction on the reappearance of the response. J. comp. physiol. Psychol., 1952, 45, 589-599.

KAMIN, L. J. The retention of an incompletely learned avoidance response. J. comp. physiol. Psychol., 1957, 50, 457-460.

KAMIN, L. J. Retention of an incompletely learned avoidance response: Some further analyses. J.comp. physiol.Psychol., 1963, 56, 713-718.

KOPPENAAL, R. J. Time changes in the strengths of A-B, A-C lists: Spontaneous recovery? J.verb. Learn. verb. Beh., 1963,2 , 310-319.

LEWIS, D. J., \& ADAMS, H. E. Retrograde amnesia from conditioned competing responses. Science, 1963, 141, 516-517.

UNDERWOOD, B. J. "Spontaneous recovery" of verbal associations. J. exp. Psychol., 1948, 38, 429-439.

\section{Note}

1. This work was carried out at the University of Manitoba, and was supported by Grants APA-76 and -77 from the National Research Council of Canada. R. M. Cooper was supported by United States Public Health Service Grant 2M6418 while this article was being prepared for publication. We are indebted to L. Wilgosh and S. Folb for help in testing the animals. 